\title{
PENGEMBANGAN WILAYAH ACEH BESAR MELALUI SEKTOR UNGGULAN: PERSEPSI STAKEHOLDER
}

\author{
Regional Development of Aceh Besar through Leading Sector: Stakeholder Perception \\ Myna Agustina Yusuf ${ }^{1}$, Irin Caisarina ${ }^{2}$ dan Sanna Nadia $^{3}$ \\ 1) Program Studi Perencanaan Wilayah dan Kota, Fakultas Teknik USK (mynayusuf@unsyiah.ac,id) \\ 2) Program Studi Perencanaan Wilayah dan Kota, Fakultas Teknik USK (irincaisarina@unsyiah.ac.id) \\ 3) Program Studi Perencanaan Wilayah dan Kota, Fakultas Teknik USK (sannanadia27@gmail.com)
}

\begin{abstract}
ABSTRAK
Salah satu tujuan pengembangan wilayah adalah meningkatkan ekonomi dan mensejahterakan masyarakat. Kabupaten Aceh Besar merupakan salah satu Kabupaten di Provinsi Aceh yang masih belum maju dalam pengembangan wilayahnya jika dibandingkan dengan kota/kabupaten di sekitarnya. Pengembangan wilayah Kabupaten Aceh Besar cukup penting dilakukan terutama memiliki sektor beragam dalam wilayah administratif yang sangat luas yaitu 404,35 $\mathrm{Km} 2$. Pengembangan dapat dilakukan melalui sektor unggulan wilayah yang menggambarkan potensi daya saing kompetitif dan spesialisasi dalam lingkup kabupaten. Penelitian ini bertujuan untuk menentukan sektor unggulan daerah Kabupaten Aceh Besar, memetakan potensi dan peluangnya kemudian merekomendasikan pengembangan wilayahnya berdasarkan persepsi stakeholder. Data yang digunakan adalah Produk Domestik Regional Bruto (PDRB) Kabupaten dan hasil wawancara. Sektor unggulan ditetapkan dalam tiga tahapan analisis sektor ekonomi wilayah yaitu Location Quotient (LQ), Shift Share, dan Klassen Typology. Perumusan strategi didasarkan atas olahan hasil wawancara dan analisis SWOT. Hasil analisis sektor unggulan menunjukkan yang memiliki pertumbuhan serta kontribusi terbesar terhadap PDRB Kabupaten Aceh Besar adalah kontruksi, sektor transportasi dan pergudangan, sektor perdagangan besar dan eceran; reparasi mobil dan motor, sektor informasi dan komunikasi serta sektor real estate. Potensi utamanya adalah lokasinya yang strategis, namun kualitas SDM rendah sebagai kelemahan utamanya. Langkah pengembangan wilayah yang dapat dilakukan adalah membangun tenaga kerja memiliki kualitas kompetensi tinggi, mengembangkan inovasi teknologi BIM (Building Information Modelling), meningkatkan produksi komoditas yang berpotensi dan memiliki nilai jual tinggi, meningkatkan potensi SDM untuk memaksimalkan potensi, melakukan pengembangan sistem transportasi yang terintegrasi dengan transportasi Kota Banda Aceh, meningkatkan pembangunan infrastruktur yang mendukung pengembangan informasi dan komunikasi, dan melakukan pengendalian pembangunan perumahan.
\end{abstract}

Kata-kata kunci: Pengembangan Wilayah, Sektor Unggulan, Stakeholder

\begin{abstract}
One of the objectives of regional development is to improve the economy and prosper the community. Aceh Besar Regency is one of the regencies in Aceh Province which is still not advanced in its regional development when compared to its surrounding cities/regencies. Regional development through existing sectors is quite important, especially Aceh Besar Regency has various sectors in a wide administrative area of $404.35 \mathrm{Km} 2$. Development can be carried out through regional superior sectors that describe the potential for competitiveness and specialization within the district. This study aims are to determine the leading sector of the Aceh Besar Regency, map its potential and opportunities and then recommend regional development based on stakeholder perceptions. The data used is regency Gross Regional Domestic product (GRDP) data and interviews. Leading sectors are determined based on three stages of regional economic sector analysis, namely Location Quotient (LQ), Shift Share, and Klassen Typology. The formulation of strategy is based on the results of interviews and SWOT analysis. The leading sectors based on analysis are namely the construction sector, the transportation and warehousing sector, the wholesale and retail trade sector; auto and motorcycle repair, information and communication sector and real estate sector. The main potential of Aceh Besar is its strategic location, but the quality of human resources is low as its main weakness. Regional development steps that can be taken based on stakeholder perceptions are to build a high quality of competence, develop BIM (Building Information Modeling) technology innovations, increase the production of commodities that have the potential and have high selling value, increase the potential of human resources to maximize potential, conduct development of an integrated transportation system with the transportation of Banda Aceh, increasing infrastructure development that supports the development of information and communication, and controlling housing development.
\end{abstract}

Keywords: Regional Development, Leading sector, Stakeholder

\begin{tabular}{lll}
\hline Article History & & \\
\hline Diterima (Received) & $:$ & $14-12-2021$ \\
Diperbaiki (Revised) & $:$ & $25-12-2021$ \\
Diterima (Accepted) & $:$ & $27-12-2021$
\end{tabular}




\section{PENDAHULUAN}

Salah satu tujuan dalam pengembangan wilayah yaitu memperkecil kesenjangan pertumbuhan dan ketimpangan kesejahteraan antar wilayah, dalam upaya pembangunan terorganisir masyarakat untuk meningkatkan kesejahteraannya (Mahi, 2016). Salah satu indikator kesejahteraan adalah kondisi ekonomi, yang dalam aspek regional maka dapat dilihat dari nilai Produk Domestik Regional Bruto (PDRB) yang dapat memberikan gambaran tentang keadaan perekonomian suatu wilayah melalui sektor-sektor yang ada di wilayah tersebut (Alhudori, 2017). Untuk mendukung pertumbuhan ekonominya, maka Kabupaten Aceh Besar perlu mengidentifikasi sektor-sektor yang merupakan sektor unggulan serta menjadi prioritas perencanaan pembangunan ekonomi wilayahnya. Beragamnya potensi fisik Kabupaten Aceh besar seperti pegunungan, perbukitan, dan laut tentunya juga menyimpan potensi ekonomi, tetapi pengembangan wilayah Kabupaten Aceh Besar saat ini masih kurang maju dibandingkan kabupaten-kabupaten lain di Aceh.

Pengembangan wilayah melalui penguatan sektor unggulan menjadi salah satu upaya yang dapat dilakukan untuk mendukung terciptanya kesejahteraan di Kabupaten Aceh Besar. Di sisi lain, keputusan pemangku kepentingan juga berpengaruh pada arah pembangunan wilayah. Penelitian ini berupaya mengidentifikasi sektor unggulan, melihat potensi dan kelemahan dan merangkum rekomendasi pengembangan wilayah berdasarkan persepsi stakeholder Kabupaten Aceh Besar.

\section{STUDI LITERATUR}

\subsection{Sektor Unggulan}

Kondisi ekonomi di suatu daerah dalam satu periode tertentu adalah dengan melihat data Produk Domestik Regional Bruto (PDRB) yang menjadi salah satu indikator ekonomi. Data ini menggambarkan kemampuan suatu daerah dalam mengelola sumber daya yang dimilikinya (Sirojuzilam dan Mahali, 2010). Tingkat pembangunan yang berbeda di tiap sektornya berdampak pada perbedaan pembentukan nilai PDRB. Jika suatu sektor memiliki peranan pada nilai tambah terhadap pembentukan atau pertumbuhan PDRB di suatu daerah, maka semakin tinggi laju pertumbuhan PDRB daerah tersebut.

Suatu wilayah akan memiliki nilai PDRB yang berbeda dengan daerah lalinnya tergantung kemampuan wilayah dalam mengelola potensi sektornya. Kondisi ini memberikan'gambaran bahwa nilai PDRB akan berbeda tiap sektor dan wilayah, sehingga suatu daerah akan memiliki sektor unggulan ketika memenangkan persaingan sektor yang sama dengan wilayah lain (Wahyuningtiyas dkk, 2013). Penentuan sektor unggulan dengan menggunakan data PDRB menjadi hal yang sangat penting dalam perencanaan sebagai langkah prioritas pembanguna karena terbatasnya dana pembangunan sedangkan sektor unggulan atau andalan (leading sektor) merupakan penggerak utama (prime mover) pembangunan wilayah (Zaini, 2019). Indahsari dan Listiana (2021) menyebutkan suatu sektor dapat dikatakan sektor unggulan jika: (1) memiliki spesialisasi tinggi atau mampu memenuhi kebutuhan lokal atau keluar wilayah (dapat dianalisis dengan teknik Location Quotient); (2) memiliki pertumbuhan positif dan kontribusi besar terhadap lokal wilayah dan wilayah di atasnya (dapat dianalisis dengan teknik analisis Shift Share dan Klassen Typology).

\subsection{Pengembangan Wilayah}

Pengembangan wilayah tidak terlepas dari pembangunan ekonomi daerah. Salah satu aspek yang diukur dari pembangunan ekonomi daerah adalah tumbuhnya PDRB yang selanjutnya dapat dilihat sektor unggulannya. Kebijakan yang mungkin dilakukan untuk mencapai hal tersebut adalah mengupayakan dan memanfaatkan potensi yang dimiliki daearah semaksimal mungkin (Hidayat \& Darwin, 2017) sehingga dapat menciptakan kesempatan kerja di setiap sektor ekonomi (Basuki \& Gayatri, 2009). Hal ini perlu menjadi sasaran prioritas karena seringkali kebijakan-kebijakan yang ditetapkan oleh pemerintah daerah tidak sesuai dengan potensi-potensi daerah yang bersangkutan (Vikaliana, 2017). Lebih lanjut dikemukakan oleh Hajeri dkk (2015) bahwa pemerintah daerah dalam rangka pelaksanaan otonomi daerah juga harus menentukan dan memberdayakan potensi sehingga dapat diputuskan skala prioritas pembangunan dan pengembangan wilayah.

Suatu wilayah akan mampu mempercepat pertumbuhan ekonomi wilayahnya tergantung dari keunggulan sektor-sektor ekonomi di wilayah tersebut (Rustiadi dkk, 2011). Keterkaitan antara pertumbuhan sektor unggulan yang mendorong sektor lainnya mengindikasikan bahwa pengembangan wilayah melalui pengembangan sektor menjadi salah satu pendekatan yang dapat dilakukan (Djakapermana, 2010).

Mahi (2016) menyebutkan bahwa pengembangan wilayah pada hakikatnya adalah pengembangan yang mencakup aspek-aspek 
pertumbuhan, pemerataan dan keberlanjutan dengan asumsi bahwa memperhatikan potensi pertumbuhan akan membantu meningkatkan pertumbuhan ekonomi berkelanjutan melalui pemerataan penduduk, kesempatan kerja dan produktivitas. Maka pengembangan wilayah dan pertumbuhan ekonomi memiliki hubungan timbal balik yang langkahnya harus diperhatikan oleh stakeholder.

\subsection{Stakeholder}

Stakeholder adalah suatu masyarakat, kelompok, komunitas, individu yang memiliki kepentingan dan kekuasaan atas organisasi tertentu, atau secara sederhana disebut pemangku kepentingan yang terlibat dalam isu-isu atau rencana (Prihadi, 2020). Istilah stakeholder berkembang luas ke arah pengambilan dan implementasi keputusan.

Stakeholder dalam suatu organisasi pemerintahan dikategorikan sebagai stakeholder kunci yaitu unsur eksekutif berdasarkan levelnya (legislatif atau instansi) yang memiliki wewenang dalam mengambil keputusan (Putra, 2019). Maka sebagai pihak yang memiliki wewenang perencanaan di tingkat wilayah, tentu stakeholder memiliki peran dalam pengembangan wilayah.

\section{METODOLOGI}

Metode penelitian yang digunakan adalah metode kuantitatif dan metode kualitatif. Penentuan sektor unggulan dilakukan dengan metode kuantitatif yaitu menghitung peranan sektor berdasarkan nilai PDRB harga konstan berdasarkan lapangan usaha tahun 2015 - 2019 yang diperoleh dari dokumen Badan Pusat Statistik Provinsi Aceh dan Kabupaten Aceh Besar. Data PDRB kemudian diolah dengan tiga keknik analisis ekonomi wilayah. Ketiga jenis analisis tersebut adalah analisis Location Quotient, analisis Shift Share, dan analisis Klassen Typology.

Location Quotient atau disingkat $L Q$ adalah suatu suatu analisis yang membandingkan besarnya peranan suatu sektor di suatu daerah terhadap besarnya peranan sektor tersebut secara luas/nasional (Pramono, 2021). Tujuan dari analisis
$\mathrm{LQ}$ adalah menentukan sektor sebagai sektor basis atau non-basis. Selanjutnya, analisis Shift Share adalah suatu alat analisis yang digunakan untuk mengindentifikasi sumber pertumbuhan dan produktifitas ekonomi baik dari aspek pendapatan maupun dari aspek tenaga kerja pada suatu wilayah tertentu dan membandingkannya dengan wilayah yang lebih luas pada kurun waktu tertentu (Muljarijadi, 2011; Amalia, 2012)). Keunggulan utama dari analisis ini adalah dapat diketahui perkembangan produksi atau kesempatan kerja di suatu wilayah dengan menggunakan data pada dua periode waktu. Analisis ketiga adalah Klassen Typology yang merupakan salah satu alat ekonomi regional yang dapat digunakan untuk mengetahui gambaran pola dan struktur pertumbuhan perekonomian suatu wilayah (Kusuma dkk, 2019). Analisis ini bertujuan untuk mengidentifikasi posisi sektor perekonomian Kabupaten Aceh Besar dengan memperhatikan juga kondisi perekomian Provinsi Aceh sebagai daerah atasnya atau referensinya.

Metode kualitatif dengan teknik analisis deskriptif kualitatif digunakan untuk memetakan aspek-aspek kekuatan, kelemahan, peluang dan acaman wilayah serta merangkum strategi pengembangan wilayah. Data yang digunakan adalah data primer berupa hasil wawancara stakeholder berdasarkan pertanyaan terkait aspekaspek tersebut (Tabel 1). Stakeholder ditentukan setelah sektor unggulan terpilih yang sesuai dengan wewenang atau kepentingan terhadap sektor tersebut. Data hasil wawancara melalui tahapan reduksi data yaitu transkrip dan coding, kemudian dilakukan display data dalam bentuk narasi. Selanjutnya, hasil wawancara dianalisis dengan analisis SWOT. Menurut Nur'aini (2016) analisis SWOT adalah suatu teknik klasik sederhana yang dapat memperkirakan cara terbaik dalam menentukan strategi. Dengan demikian hasil dari analisis ini dapat memberikan arahan maupun rekomendasi pengembangan wilayah Kabupaten Aceh Besar.

Tabel 1: Daftar Pertanyaan Wawancara

\begin{tabular}{ccc}
\hline No & Variabel & \\
\hline 1 & Kekuatan & $\begin{array}{l}\text { 1. } \\
\text { Jika dilihat dari faktor internal pada Kabupaten Aceh Besar, menurut Bapak/lbu hal-hal } \\
\text { apa saja yang menjadi kekuatan pada sektor unggulan terpilih? }\end{array}$ \\
& $\begin{array}{l}\text { 2. Apa kelebihan sektor ini di Kabupaten Aceh Besar dibandingkan dengan sektor yang sama } \\
\text { di wilayah lain? }\end{array}$ \\
\hline 2. & Kelemahan & $\begin{array}{l}\text { Jika dilihat dari faktor internal pada Kabupaten Aceh Besar, menurut Bapak/lbu hal-hal apa } \\
\text { yang menjadi kelemahan pada sektor unggulan terpilih? }\end{array}$ \\
\hline
\end{tabular}


3. Peluang Jika dilihat dari faktor eksternal pada sektor ini, menurut Bapak/lbu hal-hal apa yang menjadi peluang pada sektor unggulan terpilih?

4. Ancaman 1. Jika dilihat dari faktor eksternal pada sektor ini, menurut Bapak/lbu hal-hal apa yang menjadi ancaman pada sektor unggulan terpilih?

2. Kendala apa saja yang dihadapi oleh Pemerintah Aceh Besar dalam memajukan daerahnya?

$5 \quad$ Strategi 1. Apakah pembangunan di Kabupaten Aceh Besar sudah sesuai dengan RTRW?

2. Apa strategi yang cocok untuk diterapkan demi memajukan dan mempertahankan sektor unggulan yang terpilih?

\section{HASIL DAN PEMBAHASAN}

\subsection{Penetuan Sektor Unggulan}

Penentuan sektor unggulan diperoleh dengan melakukan analisis LQ, Shift Share, dan Klassen Typology. Sektor unggulan harus memiliki nilai $L Q$ lebih dari 1, Proportional shift dan differential shift bernilai positif, dan nilai pertumbuhan dan

kontribusinya lebih besar dibandingkan dengan provinsi pada analisis Klassen Typology. Setiap sektor yang memenuhi syarat tersebut diberi tanda positif $(+)$, dan yang tidak memenuhi diberi tanda negatif (-).

Tabel 2: Penentuan Sektor Unggulan

\begin{tabular}{|c|c|c|c|c|c|}
\hline No & Sektor & $\mathrm{LQ}$ & SS & KT & Hasil \\
\hline 1 & Pertanian, Kehutanan, dan Perikanan & - & + & - & Bukan Sektor Unggulan \\
\hline 2 & Pertambangan dan Penggalian & - & - & - & Bukan Sektor Unggulan \\
\hline 3 & Industri Pengolahan & - & - & - & Bukan Sektor Unggulan \\
\hline 4 & Pengadaan Listrik dan Gas & - & - & - & Bukan Sektor Unggulan \\
\hline 5 & $\begin{array}{l}\text { Pengadaan Air, Pengelolaan Sampah, Limbah } \\
\text { dan Daur Ulang }\end{array}$ & + & - & - & Bukan Sektor Unggulan \\
\hline 6 & Konstruksi & + & + & + & Sektor Unggulan \\
\hline 7 & $\begin{array}{l}\text { Perdagangan Besar dan Eceran; Reparasi Mobil } \\
\text { dan Sepeda Motor }\end{array}$ & + & + & + & Sektor Unggulan \\
\hline 8 & Transportasi dan Pergudangan & + & + & + & Sektor Unggulan \\
\hline 9 & Penyediaan Akomodasi dan Makan Minum & + & - & - & Bukan Sektor Unggulan \\
\hline 10 & Informasi dan Komunikasi & + & + & + & Sektor Unggulan \\
\hline 11 & Jasa Keuangan dan Asuransi & - & - & - & Bukan Sektor Unggulan \\
\hline 12 & Real estate & + & + & + & Sektor Unggulan \\
\hline 13 & Jasa Perusahaan & - & - & - & Bukan Sektor Unggulan \\
\hline 14 & $\begin{array}{l}\text { Administrasi Pemerintahan, Pertahanan dan } \\
\text { Jaminan Sosial Wajib }\end{array}$ & - & + & - & Bukan Sektor Unggulan \\
\hline 15 & Jasa Pendidikan & - & + & - & Bukan Sektor Unggulan \\
\hline 16 & Jasa Kesehatan dan Kegiatan Sosial & - & - & - & Bukan Sektor Unggulan \\
\hline 17 & Jasa lainnya & - & - & - & Bukan Sektor Unggulan \\
\hline
\end{tabular}

Terdapat lima sektor yang merupakan sektor unggulan di Kabupaten Aceh Besar antara lain Sektor Konstruksi, Sektor Perdagangan Besar dan Eceran; Reparasi Motor dan Mobil, Sektor Transportasi dan Pergudangan, Sektor Informasi dan Komunikasi, serta Sektor Real estate. Hasil ini menunjukkan bahwa sektor unggulan kabupaten ini mengarah kepada sektor barang dan jasa yang ternyata mendukung kegiatan lainnya seperti pertanian yang digadang sebagai ciri utama Kabupaten Aceh Besar. Kelima sektor tersebut memiliki keunggulan komparatif, pertumbuhan dan posisi perekonomian yang positif. Penguatan kelima sektor ini tidak hanya dapat berkontribusi terhadap pertumbuhan ekonomi wilayah kabupaten tetapi juga wilayah provinsi. 


\subsection{Pengembangan Wilayah}

Berdasarkan hasil analisis sektor unggulan, maka wawancara dilakukan pada lima orang stakeholder yang memiliki jabatan pada sektor unggulan terpilih. Stakeholder yang diwawancari yatu:

1. Kepala Badan Pusat Statistik (BPS) Kabupaten Aceh Besar

2. Wakil Bupati Kabupaten Aceh Besar

3. Staf Bappeda Bidang Sarana dan Prasarana

4. Sekretaris Dinas Perhubungan Aceh Besar

5. Kasi Bagian Perdagangan, Dinas Perindustrian dan Perdagangan Kabupaten Aceh Besar.

Hasil wawancara stakeholder menunjukkan bahwa potensi utama Kabupaten Aceh yaitu letaknya yang strategis, memiliki jenis usaha mikro yang beragam sehingga memungkinkan investor untuk menanamkan modalnya. Sedangkan kelemahan utama yang disampaikan para stakeholder adalah kurangnya modal SDM yang dimiliki Kabupaten Aceh Besar. Peluang yang patut diperhatikan adalah pertumbuhan ekonomi, menurut hasil wawancara dengan beberapa ahli, merupakan sasaran yang harus diprioritaskan oleh Pemerintah Daerah Kabupaten Aceh Besar. Hal ini sesuai dengan fakta bahwa kondisi perekonomian makro Kabupaten Aceh Besar kurang maju jika dibandingkan dengan kondisi perekonomian di wilayah sekitarnya. Penerapan kebijakan pembangunan daerah yang diambil oleh stakeholder untuk mendukung pertumbuhan ekonomi harus memprioritaskan kepentingan masyarakat dalam mencapai pemerataan hasil pembangunan (Basuki \& Gayatri, 2009).

Tabel 3: Analisis SWOT

\begin{tabular}{|c|c|}
\hline \multicolumn{2}{|c|}{ Faktor Internal } \\
\hline Strengths (Kekuatan) & Weaknesses (Kelemahan) \\
\hline $\begin{array}{ll}\text { - } & \text { Letak geografis yang sangat strategis karena } \\
\text { berbatasan langsung dengan Selat Malaka dan } \\
\text { Samudera Hindia yang memiliki peran sebagai } \\
\text { pintu gerbang lalu lintas perdagangan. } \\
\text { - } \quad \text { Infrastruktur dasar seperti jalan dan jembatan } \\
\text { sudah memadai untuk mendukung kegiatan } \\
\text { ekonomi rakyat. } \\
\text { - } \quad \text { Memiliki potensi sumber daya alam yang besar } \\
\text { - } \quad \text { Pentuk membantu meningkatkan sektor unggulan } \\
\text { - } \quad \text { Akses media komunikasi dan informasi yang } \\
\text { merata } \\
\text { - Memiliki usaha mikro dan menengah yang cukup } \\
\text { banyak dan beragam }\end{array}$ & $\begin{array}{ll}\text { - } & \text { Kualitas sumber daya manusia yang masih } \\
& \text { kurang. } \\
\text { - } & \text { Persentase penduduk miskin yang cukup tinggi. } \\
\text { - } & \text { Angka pengangguran yang cukup banyak. } \\
\text { - } & \text { Sarana dan prasarana publik belum memadai. } \\
\text { - } & \text { Kualitas dan akurasi data yang masih kurang. } \\
\text { - } & \text { Kualitas dan kuantitas produk unggulan daerah } \\
& \text { masih rendah. } \\
\text { - } & \text { Kawasan lindung mengalami alih fungsi lahan } \\
& \text { karena pengembang perumahan }\end{array}$ \\
\hline \multicolumn{2}{|c|}{ Faktor Eksternal } \\
\hline Opportunities (Peluang) & Threats (Ancaman) \\
\hline $\begin{array}{l}\text { - } \\
\text { Adanya dukungan penuh dari pemerintah dalam } \\
\text { memajukan sektor unggulan. } \\
\text { - } \quad \text { Perkembangan ilmu pengetahuan dan teknologi } \\
\text { guna mendorong pembangunan daerah } \\
\text { - } \quad \text { Permintaan barang yang memungkinkan } \\
\text { perdagangan ekspor keluar daerah. } \\
\text { - } \quad \text { Minat investor untuk menanamkan investasi cukup } \\
\text { tinggi }\end{array}$ & $\begin{array}{ll}\text { - } & \text { Persaingan global yang semakin tinggi. } \\
\text { - } & \text { Bencana alam }\end{array}$ \\
\hline
\end{tabular}

Hasil wawancara dengan stakeholder mengarahkan strategi pengembangan wilayah pada aspek prasarana, teknologi dan sumber daya manusia (Tabel 4). Hal ini dikarenakan sektor unggulan terpilih merupakan sektor barang dan jasa yang sangat berpengaruh pada kegiatan ekonomi wilayah lainnya di kabupaten. Penguatan SDM tentu akan meningkatkan kualitas jasa, sedangkan penguatan prasarana dan teknologi akan menguatkan stabilitas kegiatan ekonomi dalam tantangan global. 
Tabel 4: Strategi Pengembangan

\begin{tabular}{|c|c|}
\hline Sektor & Strategi Pengembangan \\
\hline Sektor Konstruksi & $\begin{array}{ll}\text { - } & \text { Mengembangkan inovasi teknologi BIM (Building Information Modelling) dalam } \\
& \text { sektor konstruksi. } \\
\text { - } & \text { Membangun tenaga kerja yang berkualitas dan memiliki kompetensi yang tinggi; }\end{array}$ \\
\hline $\begin{array}{l}\text { Sektor Perdagangan } \\
\text { Besar dan Eceran; } \\
\text { Reparasi Mobil dan } \\
\text { Motor }\end{array}$ & $\begin{array}{ll}\text { - } & \text { Meningkatkan produksi komuditas yang berpotensi dan memiliki nilai jual tinggi; } \\
\text { - } & \text { Meningkatkan potensi SDM untuk memaksimalkan potensi; }\end{array}$ \\
\hline $\begin{array}{l}\text { Sektor Transportasi } \\
\text { dan Pergudangan }\end{array}$ & $\begin{array}{l}\text { - Melakukan pengembangan sistem transportasi yang terintegrasi dengan } \\
\text { transportasi Kota Banda Aceh seperti angkutan umum berbasis jalan raya yang } \\
\text { murah, cepat, aman dan nyaman; }\end{array}$ \\
\hline $\begin{array}{l}\text { Sektor Informasi dan } \\
\text { Komunikasi }\end{array}$ & $\begin{array}{ll}\text { - Meningkatkan pembangunan infrastruktur yang mendukung pengembangan } \\
\text { informasi dan komunikasi }\end{array}$ \\
\hline Sektor Real estate & Melakukan pengendalian real estate agar jumlahnya tetap terkontrol \\
\hline
\end{tabular}

Berdasarkan tabel di atas, maka penjabaran strategi tersebut menjadi:

1. Membangun tenaga kerja yang memiliki kualitas kompetensi tinggi.

Pembangunan sumber daya manusia khususnya tenaga kerja konstruksi menjadi bertambah urgensinya karena akan terjadinya bonus demografi pada tahun 2045. Untuk menghadapi bonus demografi tersebut maka harus dilakukan pembenahan dan persiapan dari mulai sekarang, salah satunya dengan cara bekerjasama dengan perguruan tinggi Universitas Syiah Kuala, demi meningkatkan mutu tenaga kerja sehingga akan memajukan sektor-sektor unggulan di Kabupaten Aceh Besar. Diharapkan proporsi penduduk dapat didominasi oleh lulusan minimum pendidikan menengah ke atas yang memiliki kualifikasi yang sesuai untuk bekerja dan berkontribusi dalam lingkungan masyarakat. Harapan ini sesuai dengan Program Prioritas Presiden Republik Indonesia pada periode 20192024 yaitu untuk meningkatkan sumber daya manusia ( $\mathrm{sdm}$ ) yang berkualitas dan berdaya saing.

2. Mengembangkan inovasi teknologi BIM (Building Information Modelling) dalam sektor konstruksi. Langkah-langkah pengembangan sektor konstruksi diterapkan pada seluruh kelompok penduduk dalam rentang usia produktif baik dengan latar belakang teknik maupun lainnya. Data dari Badan Pusat Statistik Kabupaten Aceh Besar menunjukkan bahwa proporsi tenaga kerja di sektor konstruksi kurang baik karena sebagaian besar tenaga kerja dengan tingkat pendidikan rendah dan berasal dari luar daerah. Selain itu, kurangnya kemampuan akan IPTEK dan menggunakan software pendukung dalam pekerjaan juga menjadi persoalan yang harus disikapi sektor ini. Penggunaan teknologi saat ini penting selain untuk mempermudah pekerjaan manusia, juga untuk menyongsong era Industry 4.0 yang mendorong manusia untuk hidup berdampingan dengan teknologi. Penerapan BIM diharapkan dapat menghasilkan pekerja yang memiliki nilai tinggi dan berkompeten baik dari segi knowledge, skill dan attitude.

3. Meningkatkan produksi komuditas yang berpotensi dan memiliki nilai jual tinggi.

Strategi ini bertujuan untuk menunjang perkembangan sektor unggulan dan sektor potensial untuk meningkatkan ekspor ke wilayah lain. Peningkatan produksi di sektor pertanian, perikanan dan industri secara otomatis akan meningkatkan nilai tambah pada sektor perdagangan besar dan eceran yang merupakan sektor unggulan wilayah ini. Meskipun sektor pertanian bukan merupakan sektor unggulan, namun para stakeholder juga menganggap bawa sektor pertanian merupakan sektor yang cukup penting di Aceh Besar, hal ini karena luasnya lahan pertanian yang ada. Dengan demikian, potensi pertanian ditambah dengan dukungan pihak-pihak terkait sangat memungkinkan produk pertanian Kabupaten Aceh Besar dapat menjadi produk unggulan kabupaten, dan secara tidak langsung juga dapat mendorong perekonomian kabupaten ini.

4. Meningkatkan potensi SDM untuk memaksimalkan potensi daerah.

Strategi ini bertujuan untuk mengoptimalkan potensi utama yang dimiliki kabupten yaitu lokasi dan kondisi geografis yang strategis. Posisi 
Kabupaten Aceh Besar sebagai lintas perdagangan serta sumber daya alam dan sumber daya manusia yang ada dapat dimanfatkan sebaik mungkin. Potensi tersebut terutama sumber daya manusia dapat ditingkatkan dengan dukungan potensi lainnya sehingga dapat memaksimalkan potensi daerah serta mendorong pelaksanaan undang-undang Otonomi Daerah.

5. Melakukan pengembangan sistem transportasi yang terintegrasi dengan transportasi Kota Banda Aceh seperti angkutan umum berbasis jalan raya yang murah, cepat, aman dan nyaman. Strategi ini dibentuk karena belum adanya angkutan umum yang khusus untuk menjangkau wilayah Kabupaten Aceh Besar mengakibatkan terbatasnya mobilitas penduduk wilayah ini mengingat lokasi Kabupaten Aceh Besar yang sangat luas, maka diperlukannya angkutan umum yang akan mempermudah aksesibilitas masyarakat sehingga perekonomian wilayah ini akan semakin meningkat.

6. Meningkatkan pembangunan infrastruktur yang mendukung pengembangan informasi dan komunikasi.

Pembangunan teknologi informasi dan komunikasi memberikan dampak yang signifikan bagi seluruh sektor yang ada di Kabupaten Aceh Besar. Pembangunan teknologi komunikasi dan informasi adalah bentuk kesiapan kabupaten dalam mengahadapi tantangan global di era digital.

7. Melakukan pengendalian real estate agar jumlahnya tetap terkontrol.

Kabupten Aceh Besar sebagai wilayah urban fringe dari Kota Banda Aceh atau wilayah perbatasan kota desa berdampak pada tingginya pertumbuhan perumahan. Pengendalian real estate dapat menciptakan efisiensi pembangunan dan mencegah terjadinya konflik pemanfaatan ruang di masa mendatang. Hal ini mengingat bahwa pemanfaatan lahan untuk pembangunan perumahan seringnya belum sepenuhnya mengacu pada aturan pemanfaatan ruang yang tertuang di Rencana Tata Ruang Wilayah (RTRW) ataupun Rencana Detail Tata Ruang (RDTR), dan masih berorientasi pada mekanisme pasar sehingga berpotensi terjadi urban sprawling (pembangunan yang tidak terpola dengan baik). Pembangunan real estate yang tidak terkendali juga akan mengakibatkan semakin berkurangnya lahan pertanian, maka dari itu perlu dilakukan pengendalian pembangunan agar tetap terkontrol dan juga ramah lingkungan.

\section{KESIMPULAN}

Pembahasan diatas menunjukkan bahwa sektor unggulan yang patut menjadi target utama pengembangan wilayah Kabupaten Aceh Besar adalah Sektor Konstruksi, Sektor Perdagangan Besar dan Eceran; Reparasi Motor dan Mobil, Sektor Transportasi dan Pergudangan, Sektor Informasi dan Komunikasi, serta Sektor Real estate. Sektor-sektor ini memiliki konstribusi besar untuk kabupaten dan provinsi serta memiliki pertumbuhan yang positif.

Potensi utama sektor unggulan adalah adanya prasarana transportasi udara yang mendukung aksesibilitas dan pertumbuhan ekonomi di sekitarnya, tersedianya banyak pasar induk yang mendukung perdagangan, dan sektor konstruksi dan jasa lainnya yang mendukung kegiatan di Kota Banda Aceh sebagai ibukota provinsi. Kelemahan dari sektor-sektor unggulan terpilih adalah kualitas SDM yang masih rendah serta sarana prasarana publik yang belum memadai. Rekomendasi pengembangan wilayah menurut stakeholder adalah membangun tenaga kerja yang berkualitas, mengembangkan inovasi teknologi BIM, meningkatkan produksi komoditas, meningkatkan potensi SDM, melakukan pengembangan sistem transportasi, meningkatkan pembangunan infrastruktur informasi komunikasi, dan melakukan pengendalian real estate agar jumlahnya tetap terkontrol.

\section{UCAPAN TERIMA KASIH}

Ucapan terimaksih kepada seluruh stakeholder di Kabupaten Aceh Besar yang berkontribusi dalam penulisan penelitian ini. Serta pihak-pihak lainnya yang ikut membantu dalam seluruh proses penelitian.

\section{DAFTAR PUSTAKA}

Alhudori. (2017). Pengaruh IPM, PDRB dan Jumlah Pengangguran Terhadap Penduduk Miskin di Kota Jambi. Jurnal of Economic and Business, 1(1).

Amalia, Fitri. (2012). Penentuan Sektor Unggulan Perekonomian Wilayah Kabupaten Bone Bolango dengan Pendekatan Sektor Pembentuk PDRB. Jurnal Etikonomi, 11 (2).

Basuki, T. A. \& Gayatri, U. (2009). Penentuan Sektor Unggulan dalam Pembangunan Daerah: Studi kasus di Kabupaten Ogan Komering llir. Jurnal Ekonomi dan Studi Pembangunan, 10(1), 34-50. 
Djakapermana, R. D. (2010). Pengembangan Wilayah Melalui Pendekatan Kesisteman. Bogor: IPB Press.

Hajeri., Yurisinthae, Erlinda., \& Dolorosa, Eva. (2015). Analisis Penentuan Sektor Unggulan Kabupaten Kubu Raya. Jurnal Ekonomi Bisnis dan Kewirausahaan, 4(2), 253-269.

Hidayat, M., \& Darwin, R. (2017). Analisis Sektor Unggulan dan Pengembangan Wilayah Kabupaten Kepulauan Meranti. Jurnal Media Trend, 12(2), 156-167.

Indahsari, Kurniyati., \& Listiana, Yufita. (2021). Teknik Analisis Ekonomi Regional. Bandung: Media Sains Indonesia.

Kusama, Hendra., Sulistyono, Setyo Wahyu., \& Priyanto, Joko. (2019). Modul Ekonomi Regional. Malang: Universitas Muhammadiyah Malang.

Mahi, Ali Kabul. (2016) Pengembangan Wilayah Teori dan Aplikasi. Jakarta: Kencana.

Muljarijadi, Bagdja. (2011). Pembangunan Ekonomi Wilayah. Bandung: UNPAD Press.

Nur'aini, Fajar. (2016). Teknik Analisis SWOT. Anak Hebat Indonesia.

Putra, Indra Mahardika. (2019). Business Model and Business Plan di Era 4.0. Anak Hebat Indonesia.

Pramono, R Widodo Dwi. (2021). Modul Teknik Analisis dan Perencanaan Wilayah. Sleman: Deepublish.

Prihadi, M.Dana. (2020). Pengenalan Dasar Manajemen Publik Relasi. Jogjakarta: KBM Indonesia.

Rustiadi, Ernan., Saefulhakim, Sunsun., \& Panuju, Dyah R. (2011). Perencanaan dan Pengembangan Wilayah. Jakarta: Yayasan Pustaka Obor Rakyat.

Sirojuzilam \& Mahalli, K. (2010). Regional: pengembangan, perencanaan dan ekonomi. Medan: USU Press.

Vikaliana, Resista. (2017). Analisis Identifikasi Sektor Perekonomian sebagai Sektor Basis dan Sektor Potensial di Kota Bogor. Transparansi: Jurnal IImiah IImu Administrasi Negara, 9 (2), 198-208.

Wahyuningtyas, Rosita., Rusgiyono, Agus., \& Wilandari, Yuciana. (2013). Analisis Sektor Unggulan Menggunakan Data PDRB (Studi Kasus BPS Kabupaten Kendal Tahun 20062010). Jurnal Gaussian, 2(3), 2019-228.

Zaini. (2019). Pengembangan Sektor Unggulan di Kalimantan Timur. Sleman: Deepublish.
Kutipan Artikel

Yusuf, M. A., Caisarina, I., \& Nadi, S. (2021),

Pengembangan Wilayah melalui Sektor Unggulan:

Persepsi Stakeholder (Studi Kasus: Kabupaten Aceh

Besar), Rumoh, Vol: 11, No: 2, Hal: 55-62:

Desember. DOI:

http://doi.org/10.37598/rumoh.v11i2.165 